\title{
Using Unsupervised Machine Learning to Identify Age- and Sex-Independent Severity Subgroups Among Patients with COVID-19: Observational Longitudinal Study
}

Julián Benito-León $^{1^{*}}, \mathrm{MD}, \mathrm{PhD} ; \mathrm{M}^{\mathrm{a}}$ Dolores del Castillo ${ }^{2 *}, \mathrm{PhD}$; Alberto Estirado ${ }^{3}$, BSc; Ritwik Ghosh ${ }^{4}$, MD; Souvik Dubey $^{5}, \mathrm{MD}, \mathrm{DM}$; J Ignacio Serrano ${ }^{2 *}, \mathrm{PhD}$

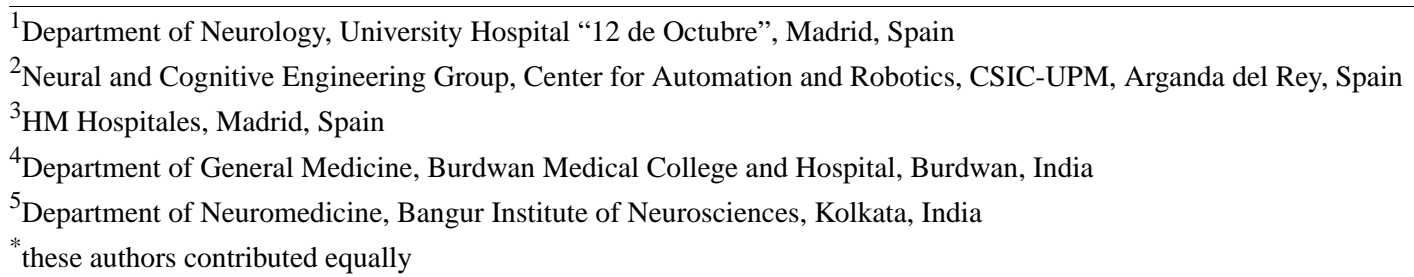

\section{Corresponding Author:}

Julián Benito-León, MD, PhD

Department of Neurology

University Hospital "12 de Octubre"

Avenida de Córdoba s/n

Madrid, 28041

Spain

Phone: 34639154069

Email: jbenitol67@gmail.com

\section{Abstract}

Background: Early detection and intervention are the key factors for improving outcomes in patients with COVID-19.

Objective: The objective of this observational longitudinal study was to identify nonoverlapping severity subgroups (ie, clusters) among patients with COVID-19, based exclusively on clinical data and standard laboratory tests obtained during patient assessment in the emergency department.

Methods: We applied unsupervised machine learning to a data set of 853 patients with COVID-19 from the HM group of hospitals (HM Hospitales) in Madrid, Spain. Age and sex were not considered while building the clusters, as these variables could introduce biases in machine learning algorithms and raise ethical implications or enable discrimination in triage protocols.

Results: From 850 clinical and laboratory variables, four tests-the serum levels of aspartate transaminase (AST), lactate dehydrogenase (LDH), C-reactive protein (CRP), and the number of neutrophils-were enough to segregate the entire patient pool into three separate clusters. Further, the percentage of monocytes and lymphocytes and the levels of alanine transaminase (ALT) distinguished cluster 3 patients from the other two clusters. The highest proportion of deceased patients; the highest levels of AST, ALT, LDH, and CRP; the highest number of neutrophils; and the lowest percentages of monocytes and lymphocytes characterized cluster 1. Cluster 2 included a lower proportion of deceased patients and intermediate levels of the previous laboratory tests. The lowest proportion of deceased patients; the lowest levels of AST, ALT, LDH, and CRP; the lowest number of neutrophils; and the highest percentages of monocytes and lymphocytes characterized cluster 3.

Conclusions: A few standard laboratory tests, deemed available in all emergency departments, have shown good discriminative power for the characterization of severity subgroups among patients with COVID-19.

(J Med Internet Res 2021;23(5):e25988) doi: 10.2196/25988

\section{KEYWORDS}

COVID-19; machine learning; outcome; severity; subgroup; emergency; detection; intervention; testing; data set; characterization 


\section{Introduction}

The COVID-19 pandemic has brought to light the scarcity of health care resources worldwide [1]. One of the main challenges faced by health care systems while tackling this pandemic is the lack of affordable, accurate, and simple information that can allow clinicians to predict the evolution of the patients' disease sooner, upon admission to the hospital. This information might help clinicians to make early decisions regarding arrangement and organization of medical resources, as well as early interventions to improve the health outcomes of these patients.

The exhaustive and inefficiently structured amount of health data available does not permit parametric modeling in an easy way. To overcome this issue, machine learning techniques have recently been identified as promising tools in data analysis for individual class prediction, allowing us to deal with a great number of variables simultaneously and observe inherent disease-related patterns in the data [2].

Machine learning for health care is a key discipline aimed to translate large health data sets into operative knowledge in different medical fields [3-7]. The methods of this artificial intelligence paradigm can be classified as supervised or unsupervised, based on the underlying strategy used [8]. In inductive or supervised machine learning, the method builds a general class description of the target categories from a set of previously categorized examples [8]. In general, supervised learning methods are used to design classifiers from labeled samples that predict the class of an unseen new sample [8]. In the field of medicine, these methods have been applied to find prognostic and predictive biomarkers [9]. On the other hand, in unsupervised machine learning, the goal is to find the class or classes that cover the sample [8]. These methods permit the discovery of the underlying structure and relationships among unlabeled samples [8]. Unsupervised clustering techniques can obtain groups of samples so that the intrasimilarity within each group is maximized, while intersimilarity between groups is minimized [8]. They are usually applied in medicine to identify homogeneous groups of patients based on their medical records and relationships between clinical manifestations and therapeutic responses, or to detect sets of coexpressed genes, among other applications $[10,11]$.

There are several research reports using COVID-19 data sets, which focus on predicting the patients' mortality or severity by mainly using regression modeling from labeled clinical records [12-17]. Further, in a multicenter study, using supervised machine learning, a personalized COVID-19 mortality risk score for hospitalized patients upon admission has been proposed [18]; however, in that study [18], the reason for choosing only a subset of the recorded clinical variables to build their model was not explained. Therefore, the algorithm might have been biased, even by the expert's knowledge. In all of these studies [12-18] and in a study based on cluster analysis [19], demographics, such as age and sex, were considered as key variables in their prediction models. By contrast, these variables were deliberately excluded from the training data set in this study, in which we used an unsupervised machine learning method for data handling.

Health agencies recommend that clinical decisions should be made based on an individual's biological age rather than chronological age [20,21]. There are multiple physiological and molecular markers for estimation of biological aging that can predict life span [22]. Besides these markers, the heterogeneity of eating habits, physical and mental conditions, and therapeutics have an influence on the overall health state, making biological aging a heterogeneous process too.

Frailty and multi-morbidities, as measures of biological aging, have been found to be risk factors for mortality independent of chronological age in patients with COVID-19 [23]. New procedures for the therapeutic management of COVID-19 are required regardless chronological age [24].

Furthermore, reports about case-fatality rates for COVID-19 categorized by age groups could sentence elderly people not only to social exclusion but also to health care indifference. Considering the elderly population as a highly vulnerable group is a simple and negative stereotype that may even influence decision making in clinical resource management [25].

The prevalence and severity of COVID-19 also varies based on sex, whereby men experience higher mortality than women [26]. The severity of the disease implies that the person may need hospitalization, intensive care support, and mechanical ventilation. However, the medical treatments scheduled during hospitalization or a stay in intensive care are the same for every patient with a severe case of COVID-19, regardless age or sex [27].

Since chronological age as well as sex cannot be considered as pivotal aspects to determine an individual's health status and resilience [28], these should not be key determinants for health care or resource allocation among people suffering from COVID-19. Therefore, predictive models based on intelligent data processing that take into account a patient's age as a major determinant in health care access may be inappropriate and unethical [25].

Demographic variables (ie, age and sex) were not used in the previously published studies for building models on effective treatments based upon sex or age groups or for understanding sex or age differences [12-19]. These predictive models of severity and mortality risk for COVID-19 could be discriminating [29]. For example, consideration of the age of people in the emergency department might discriminate against older people (ie, ageism) regarding access to care, since the decision would be based purely upon the age of the patients rather than their health care needs [30].

The objective of this observational longitudinal study was to identify nonoverlapping severity subgroups (ie, clusters) among patients with COVID-19, using exclusive laboratory tests and clinical data obtained during the first medical contact in the emergency department, by means of unsupervised machine learning techniques. Age and sex were not taken into account to build the subgroups due to the ethical implications. For this purpose, we used the data set collected by the HM group of hospitals (HM Hospitales) in Madrid, Spain [31]. 


\section{Methods}

\section{Data Set}

This study is a longitudinal analysis of the data set collected by the HM group of hospitals in Madrid, Spain, in the context of the project Covid Data Save Lives [31]. The information from this data set comes from the electronic health records data system of the seven HM hospitals, located in the Community of Madrid in Spain [31]. This data set contains the anonymized records of 2310 patients, admitted to any of the seven HM hospitals, with a diagnosis of COVID-19 from March 1 to April 24, 2020. The data set includes different interactions within COVID-19 treatment processes, including detailed information on diagnoses, treatments, intensive care unit (ICU) admission, and discharge or death, among many other variables. The data set also includes diagnostic imaging and laboratory tests or records of previous medical care, if any. It also includes the drugs administered to each patient during admission (more than 60,000 records) with the dates corresponding to the first and last administration of each drug, which was identified by its brand name and classification in the Anatomical Therapeutic Chemical codes (ATC5/ATC7). Moreover, laboratory data are also included (398,884 records). Finally, the data set contains the records of the diagnostic and procedural information-coded according to the ICD-10 (International Statistical Classification of Diseases and Related Health Problems, 10th Revision) classification in its latest distributed version-for the patients referred, both for episodes of hospital admission (more than 1600 ) and for the emergencies (more than 1900) prior to those episodes, if any.

\section{Data Preprocessing}

We collected the information for each patient identifier and compiled it into one record. This included age, sex, vital signs in the emergency department, and the need or lack of need of the ICU. COVID-19 symptoms, ICD-10 codes of previous and current conditions, as well as different laboratory tests performed in the emergency department were also recorded. We also calculated, for each patient, the duration in days of the hospital stay, including ICU admission and the days from hospitalization to ICU admission. We also considered the first laboratory tests obtained from the emergency department and grouped all of the ICD-10 codes under the first three characters (ie, first letter and two subsequent numbers) of the code to reduce the number of variables and provide generalization. We codified each ICD-10 feature for inclusion in one of the following groups: present in emergency department admission, not present in emergency department admission, or developed during hospital stay.

Only patients with a discharge reason of death or recovered were included in the analyses. The patients with a discharge reason of transferred to another hospital or transferred back to the nursing home (about $3.6 \%$ of the total data set) were excluded, since no additional information was available after they left the hospital. We only selected the records (ie, patients) with no missing values on clinical data and laboratory tests, which left a final sample of 853 (37.2\% women) patients to be included in our analyses. The mean age of the sample was 67.2 (SD 15.7) years (range 21-106). Each patient had 850 variables in his or her record, including eight variables about demographics, hospitalization stay, and outcome measures; one variable about COVID-19 symptoms; 10 variables about vital signs (eg, temperature, heart rate, oxygen saturation, and systolic and diastolic blood pressure) in the emergency department; 29 laboratory tests from the emergency department (Table 1); 168 ICD-10 codes from the emergency department; and 634 ICD-10 codes during their hospital stay.

The final sample of 853 patients was similar to the excluded sample $(\mathrm{n}=1457)$ in terms of age (mean 67.2, SD 15.7 years, vs mean 67.1 , SD 17.0 years; $F_{1,2308}=1.508 ; P=.22$ ); discharge reason (selected deceased: $15.6 \%$ vs excluded deceased: $18.2 \%$; $\left.F_{1,2308}=2.474 ; P=.12\right) ; \quad$ ICU admission $(6.8 \%$ vs $7.3 \%$; $F_{1,2308}=0.003 ; P=.96$ ); or admission date (March 27, 2020, \pm 8.3 days, vs March 28, 2020, \pm 11.6 days). However, there were significant differences in terms of sex (37.2\% women vs $42.2 \%$ women; $F_{1,2308}=5.768 ; P=.02$ ) and days in hospital (mean 9, SD 6, vs mean 8, SD 7; $F_{1,2308}=4.786 ; P=.03$ ). Notwithstanding, the effect size was small for both differences $\left(\eta^{2}=0.003\right.$ and $\eta^{2}=0.002$, respectively). 
Table 1. Laboratory tests used to characterize the patients.

\begin{tabular}{|c|c|c|}
\hline Code & Description & Unit \\
\hline RDW & Red cell distribution width & $\%$ \\
\hline BAS & Basophils & $\times 10^{3} / \mu \mathrm{L}$ \\
\hline BAS $\%$ & Percentage of basophils & $\%$ \\
\hline $\mathrm{MCHC}$ & Mean corpuscular hemoglobin concentration & $\mathrm{g} / \mathrm{dL}$ \\
\hline CREA & Creatinine & $\mathrm{mg} / \mathrm{dL}$ \\
\hline EOS & Eosinophils & $\times 10^{3} / \mu \mathrm{L}$ \\
\hline $\mathrm{EOS} \%$ & Percentage of eosinophils & $\%$ \\
\hline GLU & Glucose & $\mathrm{mg} / \mathrm{dL}$ \\
\hline AST & Aspartate transaminase & $\mathrm{U} / \mathrm{L}$ \\
\hline ALT & Alanine transaminase & $\mathrm{U} / \mathrm{L}$ \\
\hline $\mathrm{MCH}$ & Mean corpuscular hemoglobin & pg \\
\hline HCT & Hematocrit & $\%$ \\
\hline $\mathrm{RBC}$ & Red blood cells & $\times 10^{6} / \mu \mathrm{L}$ \\
\hline $\mathrm{HB}$ & Hemoglobin & $\mathrm{g} / \mathrm{dL}$ \\
\hline K & Potassium & $\mathrm{mmol} / \mathrm{L}$ \\
\hline LDH & Lactate dehydrogenase & $\mathrm{U} / \mathrm{L}$ \\
\hline LEUC & Leucocytes & $\times 10^{3} / \mu \mathrm{L}$ \\
\hline LYM & Lymphocytes & $\times 10^{3} / \mu \mathrm{L}$ \\
\hline LYM\% & Percentage of lymphocytes & $\%$ \\
\hline MONO & Monocytes & $\times 10^{3} / \mu \mathrm{L}$ \\
\hline MONO\% & Percentage of monocytes & $\%$ \\
\hline NA & Sodium & $\mathrm{mmol} / \mathrm{L}$ \\
\hline NEU & Neutrophils & $\times 10^{3} / \mu \mathrm{L}$ \\
\hline NEU\% & Percentage of neutrophils & $\%$ \\
\hline CRP & C-reactive protein & $\mathrm{mg} / \mathrm{L}$ \\
\hline PLAT & Platelet count & $\times 10^{3} / \mu \mathrm{L}$ \\
\hline BUN & Blood urea nitrogen & $\mathrm{mg} / \mathrm{dL}$ \\
\hline MCV & Mean cell volume & $\mathrm{fL}$ \\
\hline MPV & Mean platelet volume & $\mathrm{fL}$ \\
\hline
\end{tabular}

\section{Clustering}

Unsupervised automatic x-means clustering [32]-the implementation in RapidMiner Studio 9.7, Community Edition (RapidMiner, Inc) — was applied to the preprocessed data set that was previously described (see Data Preprocessing section). The algorithm determines the optimum number of clusters so that the intracluster distance of patients is at a minimum, and the intercluster distance of patients is at a maximum. The $\mathrm{x}$-means algorithm was used instead of the more common k-means algorithm to overcome the three major shortcomings of the latter [32]: poor computational scaling, manual selection of the number of clusters, and tendency to local minima. $\mathrm{X}$-means clustering determines the optimal number of clusters by the Bayesian information criterion (BIC), also known as the
Schwarz criterion, which is used to maximize the explained variance by the clusters and minimize the number of parameters (k) [32]. X-means clustering is also an improvement over $\mathrm{k}$-means clustering since it tends to create clusters formed by only one sample to minimize inertia [32]. Moreover, the later use of the Davies Bouldin index to evaluate the cluster distributions is also intended to overcome this issue since it considers a mix of both inertia and distortion to quantitatively asses the cluster models (see below). In addition, the automatic selection of the number of clusters by $x$-means clustering avoids the possible bias in the manual selection of $\mathrm{k}$ [32]. This bias is also present in hierarchical agglomerative clustering, where a threshold must be set to obtain the ultimate clusters after the hierarchy is built. Despite the fact that X-means clustering is not completely deterministic, it is certainly very stable with 
minimum variations between different runs [32] and is significantly more stable than k-means clustering. However, $\mathrm{X}$-means clustering introduces a bias. Since it uses the BIC to evaluate the cluster models in each iteration, this criterion purposely favors the models with a lower number of clusters. This means that an alternative cluster model with a better Davies Boulding index and a higher number of clusters may have been discarded. However, a higher number of clusters with a better Davies Boulding index usually implies clusters with small numbers of samples-notice that the best index would be obtained by a model of one cluster per sample-which is not desirable at all for the clinical stratification purpose aimed for in this study.

Patients were considered here as vectors with several dimensions equal to the number of variables. In this case, the number of variables taken to apply the clustering algorithm was 842 . None of the eight variables about demographics, hospital stay, and outcome measures were included. They were removed from the clustering formation because of the potential ethical controversies and biases (ie, demographics) or prospective information (ie, hospitalization stay and outcome measures). The algorithm was applied using several similarity or distance metrics between patients [33]: the Euclidean distance, the Canberra distance, the Chebyshev distance, the correlation similarity, the cosine similarity, the Dice similarity, the inner product similarity, the Jaccard similarity, the kernel Euclidean distance, the Manhattan distance, the max product similarity, the overlap similarity, the generalized divergence, the Itakura-Saito distance, the Kullback-Leibler divergence, the logarithmic loss, the logistic loss, the Mahalanobis distance, the squared Euclidean distance, and the squared loss. In spite of the fact that we could have had good similarity measure candidates a priori, based on data set characteristics such as dimensionality, the best practice was the selection based on empirical evaluation [34]. To avoid any a priori biases, we empirically tested all measures available in the software and kept the one yielding the best results.

To assess the fitness of the cluster distributions from the algorithm executions with the above metrics, the Davies Bouldin index was calculated for each one of them [35]. The Davies
Bouldin index is a common measure that evaluates cluster models [35]. It quantifies the average maximum ratio of the within-cluster scatter to the between-cluster separation for every pair of clusters in a cluster model [35]. In other words, it provides a trade-off between intercluster similarity and intracluster distance [35]. With this definition, the lower the Davies Bouldin index the lower the within-cluster scatter and the higher the between-cluster separation, which is the most desirable property of a cluster model [35]. The Davies Bouldin index allowed us to quantitatively select the best cluster model among those created, one for each similarity measure considered.

\section{Cluster Validation}

From the 1457 patients excluded due to missing values (ie, not used to obtain the clusters), we performed a validation analysis with the patients who presented no missing values in the variables that statistically differed between the three clusters obtained. Subsequently, these patients were assigned to one of the clusters previously obtained by using the best distance metric determined in the clustering process described above.

\section{Statistical Analysis}

The difference in the 850 variables between all the clusters obtained was tested using a one-way multivariate analysis of variance. Pairwise post hoc comparisons between clusters were analyzed by the Bonferroni test. Significance was accepted at the $5 \%$ level $(\alpha=.05)$. The observed power and effect size, as partial $\eta^{2}$, were reported for statistically significant differences.

\section{Results}

Table 2 shows the number of clusters and the corresponding David Bouldin index of the cluster distribution of patients obtained by the $\mathrm{x}$-means clustering algorithm for each of the similarity measures tested. Note that the lower the David Bouldin index, the better the cluster distribution (ie, higher intercluster distance and lower intracluster distance). The best cluster distribution (ie, lowest David Bouldin index) was obtained by using the Manhattan distance, which grouped the patients into three clusters. 
Table 2. Number of clusters and the corresponding David Bouldin index.

\begin{tabular}{|c|c|c|}
\hline Similarity measure & David Bouldin index & Number of clusters \\
\hline Euclidean distance & 0.948 & 3 \\
\hline Canberra distance & $\mathrm{N} / \mathrm{A}^{\mathrm{a}}$ & 1 \\
\hline Chebyshev distance & 0.966 & 3 \\
\hline Correlation similarity & 1.400 & 3 \\
\hline Cosine similarity & 1.629 & 3 \\
\hline Dice similarity & N/A & 1 \\
\hline Inner product similarity & N/A & 1 \\
\hline Jaccard similarity & 1.387 & 3 \\
\hline Kernel Euclidean distance & 1.440 & 3 \\
\hline Manhattan distance & 0.701 & 3 \\
\hline Max product similarity & N/A & 1 \\
\hline Overlap similarity & 5.099 & 4 \\
\hline Generalized divergence & 3.445 & 3 \\
\hline Itakura-Saito distance & 5.919 & 4 \\
\hline Kullback-Leibler divergence & 5.677 & 4 \\
\hline Logarithmic loss & 4.595 & 4 \\
\hline Logistic loss & 3.445 & 3 \\
\hline Mahalanobis distance & 4.595 & 4 \\
\hline Squared Euclidean distance & 3.445 & 3 \\
\hline Squared loss & 3.659 & 3 \\
\hline
\end{tabular}

${ }^{\mathrm{a}}$ N/A: not applicable; the David Bouldin index could not be calculated for these measures because they only had one cluster each.

Demographic and clinical characteristics of the patients in the three clusters are shown in Table 3. Notice that this table also shows the values of the eight variables (ie, demographics, hospital stay, and outcome measures) that were not used in the construction of the clusters (marked with a footnote in Table 3 ). Cluster 1 had a significantly higher proportion of deceased patients $(46.6 \%)$ than cluster $2(18.0 \%)$ and cluster $3(10.5 \%)$. No significant difference in the percentage of ICU admissions was found between clusters. However, the patients who were admitted to the ICU in cluster 1 stayed a significantly shorter time than patients in cluster 3 . No significant difference in sex was found between clusters. Patients in cluster 3 were significantly younger than those in cluster 1 . In addition, patients in clusters 1 and 2 presented with a significantly higher heart rate in the emergency department than those in cluster 3 . The average oxygen saturation for patients in the emergency department was significantly different between all clusters, whereby patients in cluster 1 had the lowest oxygen saturation and those in cluster 3 had the highest. With respect to previous diseases and surgical procedures, cluster 1 patients presented with a significantly higher percentage of epilepsy and emphysema than those in clusters 2 and 3 . In addition, cluster 2 patients presented with a higher percentage of previous surgical procedures, as well as previous thoracic, thoracolumbar, and lumbosacral intervertebral disc disorders, than patients in cluster 3 . Cluster 2 patients also presented with a significantly lower percentage of disorders of purine and pyrimidine metabolism than those in clusters 1 and 3. Finally, the percentage of patients who underwent surgical operations during their hospitalization was significantly higher in cluster 1 than in clusters 2 and 3.

Regarding laboratory tests, patients in cluster 1 showed significantly higher levels of serum creatinine, potassium, and blood urea nitrogen than those in clusters 2 and 3; cluster 1 patients also had a significantly higher value of red cell distribution width than did cluster 2 patients. In addition, patients in cluster 2 presented with significantly higher values of lymphocytes and serum levels of sodium, and significantly lower platelet counts than patients in cluster 3. In addition, cluster 3 patients showed lower values of mean corpuscular hemoglobin concentration and leucocytes, serum levels of alanine transaminase (ALT), and percentage of neutrophils than did patients in clusters 1 and 2. Cluster 3 patients had significantly higher values and percentages of eosinophils and percentages of lymphocytes than did patients in clusters 1 and 2. Finally, the laboratory tests that showed significant differences between all clusters were found for the serum levels of aspartate transaminase (AST) (cluster $1>$ cluster $2>$ cluster 3 ), lactate dehydrogenase (LDH) (cluster $1>$ cluster $2>$ cluster $3)$, C-reactive protein (CRP) (cluster $1>$ cluster $2>$ cluster 3 ), and the number of neutrophils (cluster $1>$ cluster $2>$ cluster $3)$. 
Table 3. Demographic and clinical characteristics of patients $(\mathrm{N}=853)$ in the three clusters.

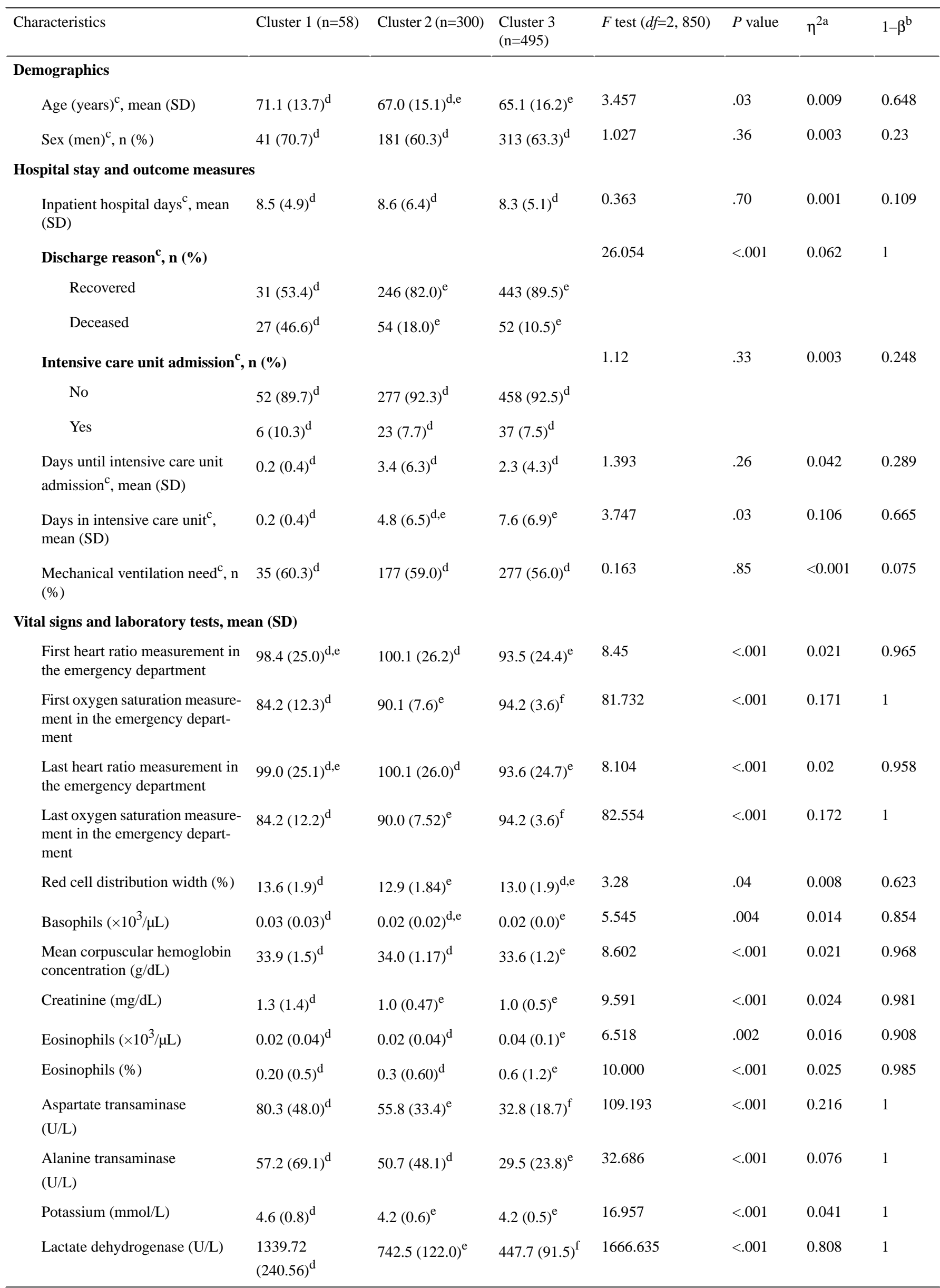




\begin{tabular}{|c|c|c|c|c|c|c|c|}
\hline Characteristics & Cluster $1(\mathrm{n}=58)$ & Cluster $2(\mathrm{n}=300)$ & $\begin{array}{l}\text { Cluster } 3 \\
(\mathrm{n}=495)\end{array}$ & $F$ test $(d f=2,850)$ & $P$ value & $\eta^{2 \mathrm{a}}$ & $1-\beta^{\mathrm{b}}$ \\
\hline Leucocytes $\left(\times 10^{3} / \mu \mathrm{L}\right)$ & $9.9(4.8)^{\mathrm{d}}$ & $8.5(4.2)^{\mathrm{d}}$ & $6.9(5.2)^{\mathrm{e}}$ & 13.055 & $<.001$ & 0.032 & 0.997 \\
\hline Lymphocytes $\left(\times 10^{3} / \mu \mathrm{L}\right)$ & $1.0(0.5)^{\mathrm{d}, \mathrm{e}}$ & $1.0(0.6)^{\mathrm{d}}$ & $1.3(2.1)^{\mathrm{e}}$ & 3.692 & .03 & 0.009 & 0.679 \\
\hline Lymphocytes (\%) & $12.6(7.8)^{\mathrm{d}}$ & $14.0(7.7)^{\mathrm{d}}$ & $20.0(9.8)^{\mathrm{e}}$ & 46.962 & $<.001$ & 0.106 & 1 \\
\hline Monocytes (\%) & $5.1(2.9)^{\mathrm{d}}$ & $6.6(3.9)^{\mathrm{d}}$ & $8.7(4.8)^{\mathrm{e}}$ & 29.321 & $<.001$ & 0.069 & 1 \\
\hline Sodium (mmol/L) & $136.2(7.1)^{\mathrm{d}, \mathrm{e}}$ & $136.2(4.4)^{\mathrm{d}}$ & $137.2(4.6)^{\mathrm{e}}$ & 4.016 & .02 & 0.01 & 0.718 \\
\hline Neutrophils $\left(\times 10^{3} / \mu \mathrm{L}\right)$ & $8.4(4.7)^{\mathrm{d}}$ & $6.9(4.0)^{\mathrm{e}}$ & $4.9(2.7)^{\mathrm{f}}$ & 45.584 & $<.001$ & 0.103 & 1 \\
\hline Neutrophils (\%) & $81.8(10.2)^{\mathrm{d}}$ & $78.8(9.9)^{\mathrm{d}}$ & $70.4(11.9)^{\mathrm{e}}$ & 62.070 & $<.001$ & 0.135 & 1 \\
\hline $\begin{array}{l}\text { C-reactive protein } \\
(\mathrm{mg} / \mathrm{L})\end{array}$ & $206.1(131.7)^{\mathrm{d}}$ & $152.1(110.0)^{\mathrm{e}}$ & $64.2(63.7)^{\mathrm{f}}$ & 12.930 & $<.001$ & 0.223 & 1 \\
\hline Platelet count $\left(\times 10^{3} / \mu \mathrm{L}\right)$ & $229.0(92.2)^{\mathrm{d}, \mathrm{e}}$ & $236.3(96.6)^{\mathrm{d}}$ & $210.3(87.2)^{\mathrm{e}}$ & 7.541 & .001 & 0.019 & 0.944 \\
\hline Blood urea nitrogen (mg/dL) & $58.9(56.6)^{\mathrm{d}}$ & $41.8(29.0)^{\mathrm{e}}$ & $40.5(29.7)^{\mathrm{e}}$ & 7.579 & .001 & 0.019 & 0.945 \\
\hline \multicolumn{8}{|l|}{ Diseases and surgical procedures, $n(\%)$} \\
\hline $\begin{array}{l}\text { Previous history of disorders of } \\
\text { purine and pyrimidine } \\
\text { metabolism }\end{array}$ & $4(6.9)^{\mathrm{d}}$ & $4(1.3)^{\mathrm{e}}$ & $25(5.1)^{\mathrm{d}}$ & 4.179 & .02 & 0.01 & 0.736 \\
\hline $\begin{array}{l}\text { Previous history of epilepsy and } \\
\text { recurrent seizures }\end{array}$ & $3(5.2)^{\mathrm{d}}$ & $4(1.3)^{\mathrm{e}}$ & $2(0.4)^{\mathrm{e}}$ & 5.660 & .004 & 0.014 & 0.862 \\
\hline Previous history of emphysema & $3(5.2)^{\mathrm{d}}$ & $2(0.7)^{\mathrm{e}}$ & $2(0.4)^{\mathrm{e}}$ & 6.663 & .001 & 0.017 & 0.914 \\
\hline $\begin{array}{l}\text { Previous history of thoracic, tho- } \\
\text { racolumbar, and lumbosacral in- } \\
\text { tervertebral disc disorders }\end{array}$ & $0(0)^{\mathrm{d}, \mathrm{e}}$ & $9(3.0)^{\mathrm{d}}$ & $3(0.6)^{\mathrm{e}}$ & 4.385 & .01 & 0.011 & 0.758 \\
\hline $\begin{array}{l}\text { Previous history of surgical pro- } \\
\text { cedures }\end{array}$ & $0(0)^{\mathrm{d}, \mathrm{e}}$ & $4(1.3)^{\mathrm{d}}$ & $0(0)^{\mathrm{e}}$ & 3.753 & .02 & 0.009 & 0.686 \\
\hline $\begin{array}{l}\text { Surgical operations during the } \\
\text { current hospitalization }\end{array}$ & $3(5.2)^{\mathrm{d}}$ & $2(0.7)^{\mathrm{e}}$ & $4(0.8)^{\mathrm{e}}$ & 4.880 & .008 & 0.012 & 0.804 \\
\hline
\end{tabular}

${ }^{\mathrm{a}}$ Effect size.

${ }^{\mathrm{b}}$ Observed power.

${ }^{\mathrm{c}}$ These variables were not used for the cluster construction.

${ }^{\mathrm{d}-\mathrm{f}}$ Values in the same row, but in different columns, that do not share footnote letters were significantly different after Bonferroni post hoc correction; values in the same row, but in different columns, that share footnote letters were not significantly different.

For a clearer characterization of the clusters, Figure 1 shows a radar chart with the variables (ie, hospital stay, outcome measures, and laboratory tests) that showed statistically significant differences among the clusters and a medium or high effect size $\left(\eta^{2}>0.06\right)$ [36].

A web-based cluster assignment tool, based on the results reported here, can be found online [37].

To test the robustness of the identified clusters, we performed a validation analysis using the initially excluded patients who did not have missing values in the variables that statistically differed among the three clusters (Table 3 ). Specifically, it was based on six variables (ie, first and last oxygen saturation measurement in the emergency department, AST, LDH, neutrophils, and CRP). For this purpose, we selected 349 patients who were initially excluded and who were assigned to one of the three previously identified clusters by the minimum Manhattan distance to the average values of the six mentioned variables of those clusters. Table 4 shows the differences in demographics, hospital stay, and outcome measures in the three clusters. Indeed, the clusters initially obtained were consistent with the clusters assigned in the validation analysis in terms of age, sex, hospital stay, and outcome measures. Specifically, cluster 1 was the one with the oldest and with the highest proportion of deceased patients. By contrast, cluster 3 was the one with the youngest and with the lowest proportion of deceased patients. 
Figure 1. Hospital stay, outcome measures, and laboratory tests that showed statistically significant differences among clusters with a medium or high effect size $\left(\eta^{2}>0.06\right)$. Note that some variables are scaled (transformation between brackets) for the sake of graph legibility. ALT: alanine transaminase; AST: aspartate transaminase; CRP: C-reactive protein; ICU: intensive care unit; LDH: lactate dehydrogenase.

$\longrightarrow$ Cluster $1 \quad \cdots-\cdots$ Cluster $2 \quad-$ 口- Cluster 3

a $<->$ b: Statistically significant

difference between $a$ and $b$

\section{$\%$ Deceased}

$1<>2$

$1<->3$

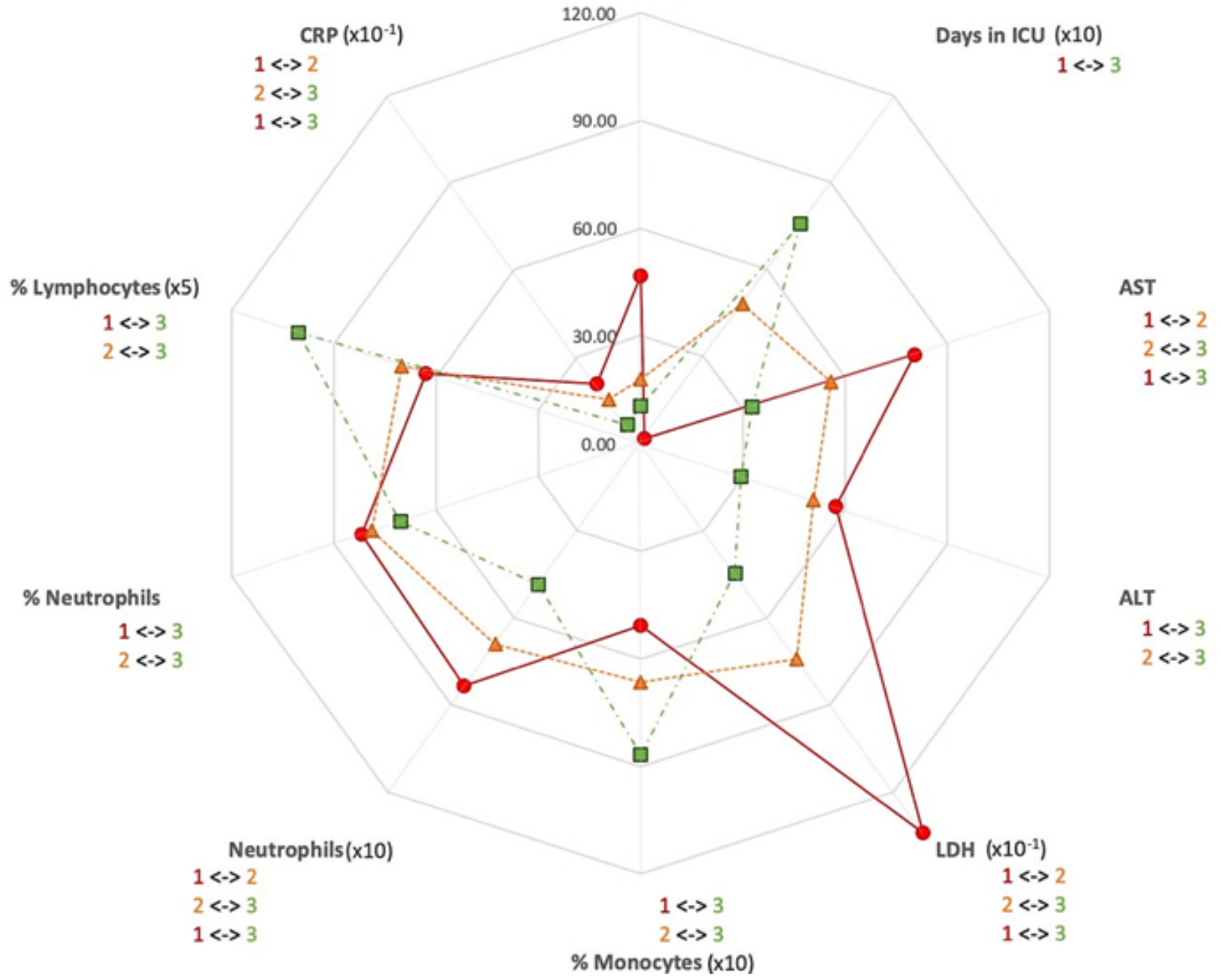


Table 4. Demographics as well as hospital stay and prognosis of the patients $(n=349)$ selected for the validation analysis in the three clusters.

\begin{tabular}{|c|c|c|c|c|c|c|c|}
\hline Characteristics & $\begin{array}{l}\text { Cluster } 1 \\
(\mathrm{n}=18)\end{array}$ & $\begin{array}{l}\text { Cluster } 2 \\
(\mathrm{n}=112)\end{array}$ & $\begin{array}{l}\text { Cluster } 3 \\
(\mathrm{n}=219)\end{array}$ & $F$ test $(d f)$ & $P$ value & $\eta^{2 \mathrm{a}}$ & $1-\beta^{b}$ \\
\hline \multicolumn{8}{|l|}{ Demographics } \\
\hline Age (years), mean (SD) & $72.8(14.2)^{\mathrm{c}, \mathrm{d}}$ & $71.3(14.3)^{\mathrm{c}}$ & $64.2(15.8)^{\mathrm{d}}$ & $9.414(2,346)$ & $<.001$ & 0.052 & 0.979 \\
\hline Sex (men), n (\%) & $14(77.8)^{\mathrm{c}}$ & $68(60.7)^{\mathrm{c}}$ & $123(56.2)^{\mathrm{c}}$ & $1.738(2,346)$ & .18 & 0.01 & 0.364 \\
\hline \multicolumn{8}{|l|}{ Hospital stay and outcome measures } \\
\hline $\begin{array}{l}\text { Inpatient hospital days, mean } \\
\text { (SD) }\end{array}$ & $9.1(6.4)^{\mathrm{c}}$ & $9.3(5.9)^{\mathrm{c}}$ & $8.0(5.3)^{\mathrm{c}}$ & $2.320(2,346)$ & .10 & 0.013 & 0.469 \\
\hline Discharge reason, $\mathrm{n}(\%)$ & & & & $22.025(2,346)$ & $<.001$ & 0.113 & 1 \\
\hline Recovered & $8(44.4)^{\mathrm{c}}$ & $80(71.4)^{\mathrm{d}}$ & $200(91.3)^{\mathrm{e}}$ & & & & \\
\hline Deceased & $10(55.6)^{\mathrm{c}}$ & $32(28.6)^{\mathrm{d}}$ & $19(8.7)^{\mathrm{e}}$ & & & & \\
\hline \multicolumn{2}{|c|}{ Intensive care unit admission, $n(\%)$} & & & $4.268(2,346)$ & .02 & 0.024 & 0.743 \\
\hline No & $16(88.9)^{\mathrm{c}, \mathrm{d}}$ & $101(90.2)^{\mathrm{c}}$ & $213(97.3)^{\mathrm{d}}$ & & & & \\
\hline Yes & $2(11.1)^{\mathrm{c}, \mathrm{d}}$ & $11(9.8)^{\mathrm{c}}$ & $6(2.7)^{\mathrm{d}}$ & & & & \\
\hline $\begin{array}{l}\text { Days until intensive care unit } \\
\text { admission, mean (SD) }\end{array}$ & $6.5(7.8)^{\mathrm{c}}$ & $4.1(3.9)^{\mathrm{c}}$ & $6.3(13.7)^{\mathrm{c}}$ & $0.170(2,16)$ & .84 & 0.021 & 0.072 \\
\hline $\begin{array}{l}\text { Days in intensive care unit, } \\
\text { mean (SD) }\end{array}$ & $4.5(0.7)^{\mathrm{c}}$ & $3.8(4.5)^{\mathrm{c}}$ & $3.2(4.6)^{\mathrm{c}}$ & $0.082(2,16)$ & .92 & 0.01 & 0.06 \\
\hline $\begin{array}{l}\text { Mechanical ventilation need, } \mathrm{n} \\
(\%)\end{array}$ & $12(66.7)^{\mathrm{c}}$ & $54(48.2)^{\mathrm{c}}$ & $96(43.8)^{\mathrm{c}}$ & $1.854(2,346)$ & .16 & 0.011 & 0.385 \\
\hline
\end{tabular}

${ }^{\mathrm{a}}$ Effect size.

bobserved power.

${ }^{\mathrm{c}-\mathrm{e}}$ Values in the same row, but in different columns, that do not share footnote letters were significantly different after Bonferroni post hoc correction; values in the same row, but in different columns, that share footnote letters were not significantly different.

\section{Discussion}

With the application of an unsupervised machine learning approach, we could identify and segregate patients with COVID-19 into subgroups depending on the severity of disease, simply by using standard laboratory tests performed during the first medical assessment in the emergency department. We found that inflammatory (ie, CRP), hematologic (ie, number of neutrophils and percentage of monocytes and lymphocytes), and serum biochemical abnormalities (ie, AST, ALT, and LDH), mainly indicating liver dysfunction, detected upon admission to the hospital could predict the severity of the disease. From a sum of 850 variables collected in the emergency department, only four standard laboratory tests (ie, serum levels of AST, $\mathrm{LDH}, \mathrm{CRP}$, and the number of neutrophils) were enough to segregate these patients into three separate clusters. Of these, the levels of LDH had the biggest effect size, practically allowing us to differentiate the three clusters linearly. Further, the percentage of monocytes and lymphocytes as well as ALT distinguished cluster 3 patients (ie, less severe) from patients in the other two clusters. Cluster 1 was characterized by the highest proportion of deceased patients; the highest levels of AST, ALT, LDH and CRP; the highest number of neutrophils; and the lowest percentages of monocytes and lymphocytes (Figure 1). Cluster 2 included a lower proportion of deceased patients and intermediate values of the previous laboratory tests (Figure 1). Finally, the lowest proportion of deceased patients; the lowest levels of AST, ALT, LDH and CRP; the lowest number of neutrophils; and the highest percentages of monocytes and lymphocytes characterized cluster 3 (Figure 1).

Our results have several clinical implications. First, age and sex were not considered while building the clusters. Therefore, our unsupervised machine learning approach, based exclusively on the performance of simple laboratory tests at a primordial stage, would permit the establishment of a strategy for rationing of health care resources and to establish a triage protocol, which would support medical decisions in a transparent and ethical way. Second, since the analyzed data are from standard laboratory tests, this method would be especially valuable for underdeveloped and developing regions that lack medical resources and have affordability issues. Finally, we could tailor treatment to each severity group accordingly at a primordial stage (ie, in the emergency department). For example, more aggressive therapies could be considered in patients classified in cluster 1 (ie, the most severe) and not in those in cluster 3 (ie, the least severe).

Initially, SARS-CoV-2 was primarily considered a respiratory pathogen. However, with time, it has behaved like a virus with the potential to cause multisystem involvement [38,39]. Specifically, hepatic injury related to COVID-19 is only beginning to unravel. Elevated liver injury indicators, particularly AST, are strongly associated with a higher mortality risk in patients with COVID-19 [40]. Of note, high serum levels 
of LDH predict higher in-hospital mortality in patients with severe and critical condition of COVID-19 [41]. Significant increased CRP levels in the early stages of COVID-19 are correlated with the severity of disease and the degree of internal tissue pathologies [42]. Further, a significant increase in the number of neutrophils with a decrease in the number of lymphocytes, monocytes, and eosinophils may indicate clinical worsening and increased risk of a poor outcome among patients with COVID-19 [43]. Taken together, the presence of elevated biomarkers of inflammation and that of liver injury in serum, as well as the number of neutrophils at admission, are indicative of multiple organ failure in patients with COVID-19 that could lead to death. Our laboratory findings are in agreement with other previous studies worldwide [44-46].

Although one previous multicenter study, based on the analyses of demographics, comorbidities, vital signs, and laboratory test results upon admission, that evaluated the prediction of disease course in patients with COVID-19 has been undertaken [18], there remains much to learn about applying machine learning techniques regarding this novel infectious disease. Comparison with that study is difficult, as they had used different variables and techniques. The accuracy of the model could be influenced by several factors, including the methods. Feature extraction methods, feature selection or classification tools, number of subjects, and demographics are also important considerations. Besides, most COVID-19 diagnostics and prognostic models that have evolved to date have a high risk of generating bias leading to inequality [47], mainly due to the high influence of demographic variables, especially age and sex, in those models and to the nonblinded nature of the supervised machine learning approach between predictors and outcome measures. In fact, our results confirmed that age and sex had a similar and low discriminant value to separate the three clusters (Table 3). Nevertheless, the results obtained in our study are in line with most previous work based on supervised machine learning techniques in COVID-19 [18,47].

The study should be interpreted within the context of several limitations. First, the patients in this study may represent a selected group of patients with COVID-19 (ie, patients with a more severe disease, since all of them were admitted to the hospital); hence, it is questionable as to what extent our results could be generalized to the entire population of patients with COVID-19. The reason for this was that the extreme circumstances in our hospitals at the peak of this pandemic permitted the hospitalization of only the most severe cases. Notwithstanding, our aim was to detect severity subgroups among patients with COVID-19 upon admission to the hospital. Second, we only kept the records (ie, patients), laboratory tests, and clinical variables from 853 patients from the data set due to the high number of missing values in the remaining 1457 patients. Despite this, the results have been robust.

In closing, to the authors' knowledge, the work presented in this paper is the first attempt to use unsupervised machine learning to identify severity subgroups among patients with COVID-19 upon admission. A few affordable, simple, and standard laboratory tests, which are expected to be available in any emergency department, have shown promising discriminative power for characterization of severity subgroups among patients with COVID-19. We have also provided an online severity cluster assignment tool for patients with COVID-19 who are admitted to the emergency department [37]. This could permit the classification of patients according to severity subgroups and, hence, initiate earlier interventions.

\section{Authors' Contributions}

JBL collaborated in the conception, organization, and execution of the research project; the writing of the first draft of the manuscript; and the review and critique of the manuscript. MDDC collaborated in the conception and organization of the research project, the statistical analyses, writing of the first draft of the manuscript, and the review and critique of the manuscript. AE collaborated in the organization of the research project and the review and critique of the manuscript. RG collaborated in the organization of the research project and the review and critique of the manuscript. SD collaborated in the organization of the research project and the review and critique of the manuscript. JIS collaborated in the conception and organization of the research project, the statistical analyses, the writing of the first draft of the manuscript, and the review and critique of the manuscript.

\section{Conflicts of Interest}

None declared.

\section{References}

1. Joebges S, Biller-Andorno N. Ethics guidelines on COVID-19 triage-an emerging international consensus. Crit Care 2020 May 06;24(1):201 [FREE Full text] [doi: 10.1186/s13054-020-02927-1] [Medline: 32375855]

2. Rajkomar A, Dean J, Kohane I. Machine learning in medicine. N Engl J Med 2019 Apr 04;380(14):1347-1358. [doi: 10.1056/NEJMra1814259] [Medline: 30943338]

3. Bohr A, Memarzadeh K. The rise of artificial intelligence in healthcare applications. Artif Intell Healthc 2020:25-60. [doi: 10.1016/b978-0-12-818438-7.00002-2]

4. Waring J, Lindvall C, Umeton R. Automated machine learning: Review of the state-of-the-art and opportunities for healthcare. Artif Intell Med 2020 Apr;104:101822 [FREE Full text] [doi: 10.1016/j.artmed.2020.101822] [Medline: 32499001]

5. Serrano JI, Romero JP, Castillo MDD, Rocon E, Louis ED, Benito-León J. A data mining approach using cortical thickness for diagnosis and characterization of essential tremor. Sci Rep 2017 May 19;7(1):2190 [FREE Full text] [doi: 10.1038/s41598-017-02122-3] [Medline: 28526878] 
6. Benito-León J, Louis ED, Mato-Abad V, Sánchez-Ferro A, Romero JP, Matarazzo M, et al. A data mining approach for classification of orthostatic and essential tremor based on MRI-derived brain volume and cortical thickness. Ann Clin Transl Neurol 2019 Dec;6(12):2531-2543 [FREE Full text] [doi: 10.1002/acn3.50947] [Medline: $\underline{31769622}$ ]

7. Mato-Abad V, Labiano-Fontcuberta A, Rodríguez-Yáñez S, García-Vázquez R, Munteanu CR, Andrade-Garda J, et al. Classification of radiologically isolated syndrome and clinically isolated syndrome with machine-learning techniques. Eur J Neurol 2019 Jul;26(7):1000-1005. [doi: 10.1111/ene.13923] [Medline: 30714276]

8. Michalski RS, Bratko I, Kubat M. Machine Learning and Data Mining: Methods and Applications. Chichester, UK: John Wiley \& Sons, Ltd; 1998.

9. Parreco JP, Hidalgo AE, Badilla AD, Ilyas O, Rattan R. Predicting central line-associated bloodstream infections and mortality using supervised machine learning. J Crit Care 2018 Jun;45:156-162. [doi: 10.1016/j.jcrc.2018.02.010] [Medline: 29486341]

10. Alsuliman T, Humaidan D, Sliman L. Machine learning and artificial intelligence in the service of medicine: Necessity or potentiality? Curr Res Transl Med 2020 Nov;68(4):245-251. [doi: 10.1016/j.retram.2020.01.002] [Medline: 32029403]

11. Lopez C, Tucker S, Salameh T, Tucker C. An unsupervised machine learning method for discovering patient clusters based on genetic signatures. J Biomed Inform 2018 Sep;85:30-39 [FREE Full text] [doi: 10.1016/j.jbi.2018.07.004] [Medline: 30016722]

12. Shang Y, Liu T, Wei Y, Li J, Shao L, Liu M, et al. Scoring systems for predicting mortality for severe patients with COVID-19. EClinicalMedicine 2020 Jul;24:100426 [FREE Full text] [doi: 10.1016/j.eclinm.2020.100426] [Medline: 32766541]

13. Ioannidis JPA, Axfors C, Contopoulos-Ioannidis DG. Population-level COVID-19 mortality risk for non-elderly individuals overall and for non-elderly individuals without underlying diseases in pandemic epicenters. Environ Res 2020 Sep;188:109890 [FREE Full text] [doi: 10.1016/j.envres.2020.109890] [Medline: 32846654]

14. Fu J, Huang P, Zhang S, Yao Q, Han R, Liu H, et al. The value of serum amyloid A for predicting the severity and recovery of COVID-19. Exp Ther Med 2020 Oct;20(4):3571-3577 [FREE Full text] [doi: 10.3892/etm.2020.9114] [Medline: 32855710]

15. Hou H, Zhang B, Huang H, Luo Y, Wu S, Tang G, et al. Using IL-2R/lymphocytes for predicting the clinical progression of patients with COVID-19. Clin Exp Immunol 2020 Jul;201(1):76-84 [FREE Full text] [doi: 10.1111/cei.13450] [Medline: 32365221]

16. Zeng Z, Yu H, Chen H, Qi W, Chen L, Chen G, et al. Longitudinal changes of inflammatory parameters and their correlation with disease severity and outcomes in patients with COVID-19 from Wuhan, China. Crit Care 2020 Aug 27;24(1):525 [FREE Full text] [doi: 10.1186/s13054-020-03255-0] [Medline: 32854750]

17. Zhang C, Qin L, Li K, Wang Q, Zhao Y, Xu B, et al. A novel scoring system for prediction of disease severity in COVID-19. Front Cell Infect Microbiol 2020;10:318 [FREE Full text] [doi: 10.3389/fcimb.2020.00318] [Medline: $\underline{32582575]}$

18. Bertsimas D, Lukin G, Mingardi L, Nohadani O, Orfanoudaki A, Stellato B, Hellenic COVID-19 Study Group. COVID-19 mortality risk assessment: An international multi-center study. PLoS One 2020;15(12):e0243262 [FREE Full text] [doi: 10.1371/journal.pone.0243262] [Medline: 33296405]

19. Ye W, Lu W, Tang Y, Chen G, Li X, Ji C, et al. Identification of COVID-19 clinical phenotypes by principal component analysis-based cluster analysis. Front Med (Lausanne) 2020;7:570614 [FREE Full text] [doi: 10.3389/fmed.2020.570614] [Medline: 33282887]

20. COVID-19 decision support tool. NHS England. URL: http://prod-upp-image-read.ft.com/ 765d3430-7a57-11ea-af44-daa3def9ae03 [accessed 2021-03-22]

21. COVID-19 rapid guideline: Critical care in adults. National Institute for Health and Care Excellence (NICE). 2020 Mar 20. URL: https://www.nice.org.uk/guidance/ng159 [accessed 2021-03-22]

22. Ahadi S, Zhou W, Schüssler-Fiorenza Rose SM, Sailani MR, Contrepois K, Avina M, et al. Personal aging markers and ageotypes revealed by deep longitudinal profiling. Nat Med 2020 Jan;26(1):83-90 [FREE Full text] [doi:

10.1038/s41591-019-0719-5] [Medline: 31932806]

23. Marengoni A, Zucchelli A, Vetrano DL, Armellini A, Botteri E, Nicosia F, et al. Beyond chronological age: Frailty and multimorbidity predict in-hospital mortality in patients with coronavirus disease 2019. J Gerontol A Biol Sci Med Sci 2021 Feb 25;76(3):e38-e45 [FREE Full text] [doi: 10.1093/gerona/glaa291] [Medline: 33216846]

24. Gómez-Moreno C, Hernández-Ruiz V, Hernández-Gilsoul T, Avila-Funes JA. Clinical decision making in older adults with COVID-19 in developing countries: Looking beyond chronological age. Rev Invest Clin 2020;72(3):127-134. [doi: 10.24875/RIC.20000131] [Medline: 32584321]

25. Ehni H, Wahl H. Six propositions against ageism in the COVID-19 pandemic. J Aging Soc Policy 2020;32(4-5):515-525. [doi: 10.1080/08959420.2020.1770032] [Medline: 32491963]

26. Perrotta F, Corbi G, Mazzeo G, Boccia M, Aronne L, D'Agnano V, et al. COVID-19 and the elderly: Insights into pathogenesis and clinical decision-making. Aging Clin Exp Res 2020 Aug;32(8):1599-1608 [FREE Full text] [doi: 10.1007/s40520-020-01631-y] [Medline: 32557332] 
27. Juul S, Nielsen EE, Feinberg J, Siddiqui F, Jørgensen CK, Barot E, et al. Interventions for treatment of COVID-19: Second edition of a living systematic review with meta-analyses and trial sequential analyses (The LIVING Project). PLoS One 2021;16(3):e0248132 [FREE Full text] [doi: 10.1371/journal.pone.0248132] [Medline: $\underline{33705495]}$

28. Rahman A, Jahan Y. Defining a 'risk group' and ageism in the era of COVID-19. J Loss Trauma 2020 Apr 25;25(8):631-634. [doi: 10.1080/15325024.2020.1757993]

29. Cirillo D, Catuara-Solarz S, Morey C, Guney E, Subirats L, Mellino S, et al. Sex and gender differences and biases in artificial intelligence for biomedicine and healthcare. NPJ Digit Med 2020;3:81 [FREE Full text] [doi: 10.1038/s41746-020-0288-5] [Medline: 32529043]

30. Chang E, Kannoth S, Levy S, Wang S, Lee JE, Levy BR. Global reach of ageism on older persons' health: A systematic review. PLoS One 2020;15(1):e0220857 [FREE Full text] [doi: 10.1371/journal.pone.0220857] [Medline: 31940338]

31. Covid Data Save Lives. HM Hospitales. URL: https://www.hmhospitales.com/coronavirus/covid-data-save-lives/ english-version [accessed 2020-05-14]

32. Pelleg D, Moore A. X-means: Extending k-means with efficient estimation of the number of clusters. In: Proceedings of the 17th International Conference on Machine Learning. 2000 Presented at: 17th International Conference on Machine Learning; June 29-July 2, 2000; Stanford, CA p. 727-734 URL: http://citeseerx.ist.psu.edu/viewdoc/ download;jsessionid=B8BE3002265BD61591083E9412FB2C9B?doi=10.1.1.19.3377\&rep=rep1\&type=pdf

33. Cha SH. Comprehensive survey on distance/similarity measures between probability density functions. Int J Math Models Methods Appl Sci 2007;1(4):300-307 [FREE Full text]

34. Shirkhorshidi AS, Aghabozorgi S, Wah TY. A comparison study on similarity and dissimilarity measures in clustering continuous data. PLoS One 2015;10(12):e0144059 [FREE Full text] [doi: 10.1371/journal.pone.0144059] [Medline: 26658987]

35. Halkidi M, Batistakis Y, Vazirgiannis M. On clustering validation techniques. J Intell Inf Syst 2001;17(2):107-145. [doi: 10.1023/a:1012801612483]

36. Vacha-Haase T, Thompson B. How to estimate and interpret various effect sizes. J Couns Psychol 2004;51(4):473-481. [doi: 10.1037/0022-0167.51.4.473]

37. COVID-19 clinical severity group assessment. Neural and Cognitive Engineering Group, Automation and Robotics Center (CAR), CSIC-UPM. 2021. URL: https://g-nec.car.upm-csic.es/COVID19-severity-group-assessment/ [accessed 2021-05-02]

38. Yang X, Yu Y, Xu J, Shu H, Xia J, Liu H, et al. Clinical course and outcomes of critically ill patients with SARS-CoV-2 pneumonia in Wuhan, China: A single-centered, retrospective, observational study. Lancet Respir Med 2020 May;8(5):475-481 [FREE Full text] [doi: 10.1016/S2213-2600(20)30079-5] [Medline: 32105632]

39. Roy D, Ghosh R, Dubey S, Dubey MJ, Benito-León J, Kanti Ray B. Neurological and neuropsychiatric impacts of COVID-19 pandemic. Can J Neurol Sci 2021 Jan;48(1):9-24 [FREE Full text] [doi: 10.1017/cjn.2020.173] [Medline: 32753076]

40. Lei F, Liu Y, Zhou F, Qin J, Zhang P, Zhu L, et al. Longitudinal association between markers of liver injury and mortality in COVID-19 in China. Hepatology 2020 Aug;72(2):389-398 [FREE Full text] [doi: 10.1002/hep.31301] [Medline: 32359177]

41. Dong X, Sun L, Li Y. Prognostic value of lactate dehydrogenase for in-hospital mortality in severe and critically ill patients with COVID-19. Int J Med Sci 2020;17(14):2225-2231 [FREE Full text] [doi: 10.7150/ijms.47604] [Medline: 32922185]

42. Tan C, Huang Y, Shi F, Tan K, Ma Q, Chen Y, et al. C-reactive protein correlates with computed tomographic findings and predicts severe COVID-19 early. J Med Virol 2020 Jul;92(7):856-862 [FREE Full text] [doi: 10.1002/jmv.25871] [Medline: $\underline{\text { 32281668] }}$

43. Henry BM, de Oliveira MHS, Benoit S, Plebani M, Lippi G. Hematologic, biochemical and immune biomarker abnormalities associated with severe illness and mortality in coronavirus disease 2019 (COVID-19): A meta-analysis. Clin Chem Lab Med 2020 Jun 25;58(7):1021-1028. [doi: 10.1515/cclm-2020-0369] [Medline: 32286245]

44. Poggiali E, Zaino D, Immovilli P, Rovero L, Losi G, Dacrema A, et al. Lactate dehydrogenase and C-reactive protein as predictors of respiratory failure in CoVID-19 patients. Clin Chim Acta 2020 Oct;509:135-138 [FREE Full text] [doi: 10.1016/j.cca.2020.06.012] [Medline: 32531257]

45. Pourbagheri-Sigaroodi A, Bashash D, Fateh F, Abolghasemi H. Laboratory findings in COVID-19 diagnosis and prognosis. Clin Chim Acta 2020 Nov;510:475-482 [FREE Full text] [doi: 10.1016/j.cca.2020.08.019] [Medline: $\underline{32798514}$ ]

46. Soraya GV, Ulhaq ZS. Crucial laboratory parameters in COVID-19 diagnosis and prognosis: An updated meta-analysis. Med Clin (Engl Ed) 2020 Aug 28;155(4):143-151 [FREE Full text] [doi: 10.1016/j.medcle.2020.05.004] [Medline: 32864456]

47. Wynants L, Van Calster B, Collins GS, Riley RD, Heinze G, Schuit E, et al. Prediction models for diagnosis and prognosis of COVID-19 infection: Systematic review and critical appraisal. BMJ 2020 Apr 07;369:m1328 [FREE Full text] [doi:

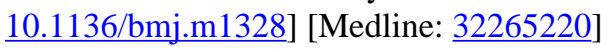

\section{Abbreviations}

ALT: alanine transaminase

AST: aspartate transaminase

BIC: Bayesian information criterion 
CRP: C-reactive protein

ICD-10: International Statistical Classification of Diseases and Related Health Problems, 10th Revision

ICU: intensive care unit

LDH: lactate dehydrogenase

Edited by C Basch; submitted 23.11.20; peer-reviewed by AV Das, X Cheng; comments to author 01.03.21; revised version received 12.03.21; accepted 25.03.21; published 27.05.21

Please cite as:

Benito-León J, del Castillo MD, Estirado A, Ghosh R, Dubey S, Serrano JI

Using Unsupervised Machine Learning to Identify Age- and Sex-Independent Severity Subgroups Among Patients with COVID-19: Observational Longitudinal Study

J Med Internet Res 2021;23(5):e25988

URL: https://www.jmir.org/2021/5/e25988

doi: $10.2196 / 25988$

PMID: $\underline{3872186}$

(CJulián Benito-León, Ma Dolores del Castillo, Alberto Estirado, Ritwik Ghosh, Souvik Dubey, J Ignacio Serrano. Originally published in the Journal of Medical Internet Research (https://www.jmir.org), 27.05.2021. This is an open-access article distributed under the terms of the Creative Commons Attribution License (https:/creativecommons.org/licenses/by/4.0/), which permits unrestricted use, distribution, and reproduction in any medium, provided the original work, first published in the Journal of Medical Internet Research, is properly cited. The complete bibliographic information, a link to the original publication on https://www.jmir.org/, as well as this copyright and license information must be included. 